\title{
Stability Monitoring of Pesticide Residues in a Chinese Cabbage Certified Reference Material
}

\author{
Seonghee Ahn, Byungjoo Kim, and Eujin Hwang \\ Division of Metrology for Quality of Life, Korea Research Institute of Standards and Science, Yuseong, Daejeon 305-340, Korea \\ *E-mail:byungjoo@kriss.re.kr \\ Received December 26, 2010, Accepted February 11, 2011
}

Key Words : Chinese cabbage CRM, Organophosphorus pesticides, Stability

Certified reference materials (CRMs) with values traceable to the International System of Units (SI) play a key role for harmonization of measurement results among laboratories. CRMs can be used for validation/verification of analytical methods employed in individual laboratories and for quality assurance or testing proficiency of laboratories. ${ }^{1-3}$ Therefore, national metrology institutes (NMIs) of developed countries have been producing CRMs of various types, which are similar to samples to be analyzed, in respect to matrix types, analytes, and their concentrations. Our laboratory, as the NMI of Korea, also has been developing CRMs for environmental, food, clinical, and material analysis. Unfortunately, (potential) users often face a problem that CRMs matching to their samples are not available. In the organic analysis field, the problem is, in most of case, due to instability of target analytes in CRMs as many organic compounds of interest are air-sensitive, light-sensitive, degrading thermally or in acidic or akalic environment, and/or evaporating out of matrix during long-term storage. ${ }^{4,5}$ Therefore, ensuring stability is a key factor for successful production of CRMs for organic analysis.

Obtaining reliable analytical results for pesticide residues in foods and agricultural products is a very important issue for food safety. However, it is well known that measurement results of pesticides, in many cases, show a strong dependence on extraction methods and sample clean-up methods employed for the analysis. ${ }^{6-9}$ In this respect, using appropriate CRMs is a secure way for a laboratory to ensure the quality of its measurement results through internal verification of its analytical procedures. However, availability of suitable matrix specific CRMs containing relevant pesticides are limited. Those limited number of CRMs available from NMIs world wide are mostly for the analysis of organochlorine pesticides in food samples as those compounds have been known to be relatively stable compared to other types of pesticides. ${ }^{10,11}$ As the agricultural use of most organochlorine pesticides was prohibited internationally, current food safety issues are focused on organophosphorus pesticides, carbamates, and pyrethroids, and the need of food CRMs for the analysis of those pesticides has been increasing. However, the inherent instability of those pesticides in food matrices has been an obstacle for developing relevant CRMs. ${ }^{4}$ At the beginning of this study, no food CRMs for the analysis of those pesticides was available, up to our knowledge. Therefore, our laboratory started a project to develop food CRMs for the analysis of organophosphorus pesticides, with anticipation to understand and overcome technical difficulties for ensuring stability of those pesticides in food matrix.

We prepared a batch of a candidate CRM for the analysis of pesticide residues in Chinese cabbage. Chinese cabbage was chosen as it represents commonly consumed leafy vegetables in Korea. Target analytes were two organophosphorus pesticides (diazinon and chlorpyrifos) and two organochlorine pesticides ( $\alpha$ - and $\beta$-endosulfans). The two organochlorine pesticides are occasionally detected above regulatory limits from vegetables produced in or imported into Korea though the agricultural use of those pesticides is prohibited. Diazinon was chosen as it is one of the most volatile organophosphorus pesticides and it is expected that its volatility may cause instability in the CRM. After initial certification of the material, its stability in various storage temperatures was monitored for three years to test whether the candidate CRM has adequate long-term stability at shelf storage condition and short-term stability at conditions for transportation to and conventional handling at users' sites. In this paper, we report the stability test results of the four pesticides in the CRM.

The Chinese cabbage CRM spiked with the four pesticides was prepared in freeze-dried and powdered form following the CRM preparation procedures maintained in our laboratories [See Experimental Section]. 150 bottles containing $15 \mathrm{~g}$ per unit were prepared and stored at $-70{ }^{\circ} \mathrm{C}$ freezer. The material was assigned as KRISS CRM \#108-05-003 (batch number 060828). The certification and the following stability test of the CRM were done by isotope dilution gas chromatography/mass spectrometry (ID-GC/MS) chosen as a primary method. ${ }^{8,11,12}$

For certification study, 10 bottles were taken from 150 bottles with even interval following the bottling order. One subsample $(1 \mathrm{~g})$ from each bottle was taken for analysis by the ID-GC/MS method. Measurement results of the 10 bottles were used for the determination of certified values and between-bottle homogeneities of the four pesticides.

While the CRM batch was stored at $-70{ }^{\circ} \mathrm{C}$, contents of the four pesticides were monitored by analyzing at least three bottles at each of several different time periods $(6,18$, 
and 30 months after certification) by using the ID-GC/MS method. For the first stability test (after 6 months of certification), some bottles were transferred from $-70{ }^{\circ} \mathrm{C}$ to $-20^{\circ} \mathrm{C}$ and $4{ }^{\circ} \mathrm{C}$ before one month and to room temperature before one week and one month of the test, and those bottles were analyzed together with three bottles stored at $-70^{\circ} \mathrm{C}$ for the isochronous stability test at those temperature. $.^{13}-20^{\circ} \mathrm{C}$ is assumed to be a possible storage condition at users' sites. $4{ }^{\circ} \mathrm{C}$ is a conventional short-term storage condition in users' sites, and room temperature is for regular use and possible maximum temperature upon transportation in an ice box.

The certified values of the four pesticides were evaluated from the measurement results of the ten selected bottles for the certification and homogeneity assessment. Among-bottle homogeneity was very excellent, showing less than $1.5 \%$ of relative standard deviation of measurement values among bottles, for diazinon, chlorpyrifos, $\beta$-endosulfan. $\alpha$-Endosulfan shows $6 \%$ of relative standard deviation among bottles. We assume that the relatively larger inhomogeneity observed for $\alpha$-endosulfan is due to analytical difficulties caused by matrix interferences. However, the homogeneity was still good for use as this value is many folders less than scattering of measurement values among regular testing
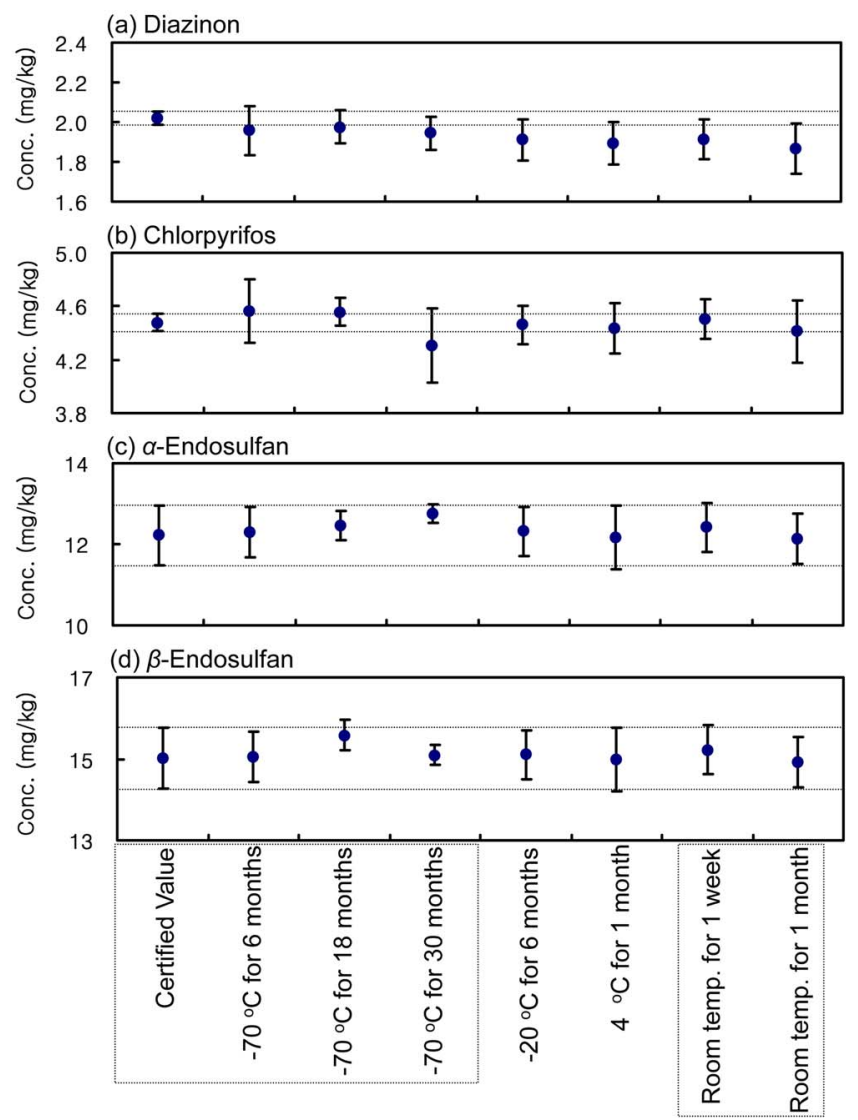

Figure 1. Stability study results of pesticide residues in a Chinese cabbage CRM stored at $-70^{\circ} \mathrm{C},-20^{\circ} \mathrm{C}, 4^{\circ} \mathrm{C}$ and room temperature for various periods; (a) diazinon, (b) chlorpyrifos, (c) $\alpha$-endosulfan, and (d) $\beta$-endosulfan. Horizontal dot lines mark expanded uncertainty intervals of corresponding certified values (with level of confidence of $95 \%$ ). laboratories. ${ }^{6,7}$ The evaluation of certified values and their uncertainty was done by following the method prescribed in our previous articles. ${ }^{5,14}$ These certified values are graphically shown in Figure 1 in parallel with stability test results.

Figure 1 shows stability test results of the four pesticides in the Chinese cabbage CRM in comparison with their certified values assigned in the initial stage of this study. The same uncertainty evaluation method employed for certified values was used for the measurement results from each stability test. Measurement results of all four pesticides from bottles stored at the shelf storage condition $\left(-70{ }^{\circ} \mathrm{C}\right)$ agree with their initial certified values within their uncertainties, indicating that the four pesticides in the CRM are stable up to 30 months of the stability monitoring period. For all four pesticides, isochronous stability test results for up to one month at $-20{ }^{\circ} \mathrm{C}, 4{ }^{\circ} \mathrm{C}$, and room temperature agree with their reference values, which are six-month $\left(\right.$ at $-70{ }^{\circ} \mathrm{C}$ ) stability test results, within their uncertainties. They also agree with their initially certified values. It proves that the four pesticides in the CRM are stable for more than one month at $-20^{\circ} \mathrm{C}, 4{ }^{\circ} \mathrm{C}$, or room temperature. It confirms the validity of the designed transportation method (under ice pack). It also proves that the CRM can be used in regular laboratory conditions, in which the material can be stored at freezer (near $-20^{\circ} \mathrm{C}$ ) and used after bring it to room temperature for a few days. While this study was at the final stage, Otake et al. reported their production of a brown rice CRM for the analysis of two pesticides, etofenprox and fenitrothion (a organophosphorus pesticide). ${ }^{4}$ They monitored and confirmed the stability of the two compounds in the material stored at $-30{ }^{\circ} \mathrm{C}$ for 9 months. Otake et al.'s results are consistent with our results.

In conclusion, we produced a Chinese cabbage CRM (KRISS CRM\# 108-05-003) for pesticide residue analysis, and monitored the stability of two organophosphorus pesticides (diazinon and chlorpyrifos) presumed to be unstable and two organochlorine pesticides ( $\alpha$ - and $\beta$-endosulfans) in the material stored at several different temperatures. This study confirmed that the four pesticides were stable up to 30 months at the shelf storage condition $\left(-70{ }^{\circ} \mathrm{C}\right)$ at the producer's site. The stability test of the CRM at $-20{ }^{\circ} \mathrm{C}, 4^{\circ} \mathrm{C}$, and room temperature verified that the CRM can be shipped under ice pack and that the CRM can be stored and used in regular testing laboratories by storing the material at $-20{ }^{\circ} \mathrm{C}$ and using it at room temperature. The results presented here have many ramifications. Along with Otake et al.'s report, this study shows that long-term stability of organophosphorus pesticides (diazinon and chlorpyrifos) can be obtained in food CRMs if they are stored at low temperature. Also, those CRM can be used in room temperature without further precaution in users' sites. Therefore, results obtained in this study build a road to produce more CRMs for the analysis of organophosphorus pesticides and/or other pesticides in foods.

\section{Experimental Section}

Preparation of Reference Material. KRISS CRM \#108- 
05-003 (batch number 060828) "Chinese cabbage powder CRM for pesticide residue analysis" was prepared based on the procedures maintained in our laboratory as the NMI of Korea. About $100 \mathrm{~kg}$ of Chinese cabbages obtained from a local market was thoroughly washed after discarding their root parts, freeze-dried, pulverized, and sieved to select powder with particle size of $50-250 \mu \mathrm{m}$. The powder was then mixed with an appropriate amount of aqueous solution containing the four target pesticides, turning into a paste form. This spiking method was chosen to make those pesticides penetrate into deep inside particles when the powder was soaked with the aqueous solution. The paste was then freeze-dried, pulverized, and sieved again. The final powder was homogenized for 10 hours of V-mixing. Around $2.4 \mathrm{~kg}$ of dried Chinese cabbage powder spiked with pesticides was obtained. The material was bottled into $60 \mathrm{~mL}$ wide-bore amber bottles in $15 \mathrm{~g}$ per unit. The bottles were purged with argon gas and tightly sealed with Teflon lined caps. A total of 150 units were prepared and stored at a $-70{ }^{\circ} \mathrm{C}$ deepfreezer.

Analytical Method. The ID-GC/MS method used for certification and stability test was briefly described here. $1 \mathrm{~g}$ of sample (corresponding to about $20 \mathrm{~g}$ of raw Chinese cabbage before drying) was spiked with an isotope standard solution containing diazinon- $d_{10}$, chlorpyrifos- $d_{10}, \alpha$-endosulfan- $d_{4}$, and $\beta$-endosulfan- $d_{4}$. The sample was then reconstituted with adding $10 \mathrm{~mL}$ of water, equilibrated for 2 hours, and extracted by shaking with $10 \mathrm{~mL}$ of acetonitrile and $10 \mathrm{~mL}$ of $n$-hexane. The $n$-hexane layer was further cleaned-up with a Florisil solid phase extraction cartridge. The extract was then analyzed by GC/MS. The GC/MS consists of a gas chromatography (Hewllet Packard 6890) and a double focusing magnetic sector mass spectrometer (Jeol JMS 700). The GC was equipped with a DB-5MS column ( $60 \mathrm{~m}$ long, $0.32 \mathrm{~mm}$ i.d, $0.25 \mathrm{~mm}$ film thickness). Helium was used as a carrier gas at a flow rate of $1.5 \mathrm{~mL} /$ min. $1 \mu \mathrm{L}$ of sample extract was loaded through its oncolumn injector. The oven temperature was programmed as following; $50{ }^{\circ} \mathrm{C}(3 \mathrm{~min})-30{ }^{\circ} \mathrm{C} / \mathrm{min}-180{ }^{\circ} \mathrm{C}(0 \mathrm{~min})-5{ }^{\circ} \mathrm{C} /$ $\min -300{ }^{\circ} \mathrm{C}(10 \mathrm{~min})$. The MS was operated with electron impact ionization at $70 \mathrm{eV}$. The four target analytes and their isotopic analogues were detected in a selected ion monitoring mode; diazinon and diazinon- $d_{10}$ with their $[\mathrm{M}]^{+}$at $\mathrm{m} / z$ 304 and 314 ; chlorpyrifos and chlorpyrifos- $d_{10}$ with their $[\mathrm{M}]^{+}$at $m / z 314$ and $324 ; \alpha-$ and $\beta$-endosulfan, and $\alpha-$ and $\beta$ endosulfan- $d_{4}$ at $\mathrm{m} / \mathrm{z} 337$ and 345. A new set of a pesticide standard solution and an isotope ratio solution was always prepared and verified in the way described in our other articles $5,8,12,14$ for the certification and stability tests done at each different time period.

\section{References}

1. Food and Agriculture Organization of the United Nations. Validation of analytical methods for food control, FAO Food and Nutrition Paper 68, 1997; ftp://ftp.fao.org/docrep/fao/007/w8420e/ w8420e00.pdf.

2. Thompson, M.; Ellison, S. L. R.; Wood, R. Pure Appl. Chem. 2002, 74,835 .

3. Emons, H.; Linsinger, T. P. J.; Gawlik, B. Trends Anal. Chem. 2001, $20,140$.

4. Otake, T.; Itoh, N.; Aoyagi, Y.; Matsuo, M.; Hanari, N.; Otsuka, S.; Yarita, T. J. Agric. Food Chem. 2009, 57, 8208.

5. Kim, B.; Park, S.; Lee, I.; Lim, Y.; Hwang, E.; So, H.-Y. Anal. Bioanal. Chem. 2010, 398, 1035.

6. Ambrus, A. Accred. Qual. Assur. 2004, 9, 288.

7. Şenyuva, H.; Gilbert, J. Trends Anal. Chem. 2006, 25, 554.

8. Kim, B.; Kim, D.-H.; Hwang, E.; So, H.-Y. Bull Korean Chem. Soc. 2002, 23, 935 .

9. Kim, D. H.; Heo, G. S.; Lee, D. W. J. Chromatogr. A 1998, 824, 63.

10. de Boer, J.; McGovern, E. Trends Anal. Chem. 2001, 20, 140.

11. Wells, D. E.; de Boer, J.; Tuinstra, L. G. M. Th.; Reutergârdh, L.; Griepink, B. Fresenius Z. Anal. Chem. 1988, 332, 591.

12. Kim, B.; Kim, D. H.; Choi, J.; So, H.-Y. Bull. Korean Chem. Soc. 1999, 20, 910.

13. ISO Guide 35 (2006) Reference materials - General and statistical principles for certification. International Organization for Standardization (ISO), Geneva, Switzerland.

14. Kim, B.; Hwang, E.; So, H.-Y.; So, H.-Y.; Son, E. K.; Kim, Y. Bull. Korean Chem. Soc. 2010, 31, 3139. 